\title{
Correction to: Bio-control potential of Trichoderma spp., against Fusarium spp., the incitants of Pokkah boeng disease of sugarcane under in-vitro conditions
}

\author{
Raghvendra Tiwari ${ }^{1,3}$ - S. K. Shukla ${ }^{1}$. V. P. Jaiswal ${ }^{1} \cdot$ Lalan Sharma $^{1} \cdot$ Deeksha Joshi $^{1} \cdot$ Kajal Chandra $^{2} \cdot$ Asha Gaur $^{1}$. \\ Abhay Srivastava ${ }^{1} \cdot$ Rajesh Kumar Tiwari $^{3}$
}

Published online: 9 August 2021

(C) Indian Phytopathological Society 2021

\section{Correction to: Indian Phytopathology \\ https://doi.org/10.1007/s42360-021-00344-0}

In this article, the affiliation 3 (Amity University, Lucknow, Uttar Pradesh, India) for the first author Raghvendra Tiwari had been missing.

The original article has been corrected.

Publisher's Note Springer Nature remains neutral with regard to jurisdictional claims in published maps and institutional affiliations.

The original article can be found online at https://doi.org/10.1007/ s42360-021-00344-0.

S. K. Shukla

sudhirshukla151@gmail.com

1 ICAR-Indian Institute of Sugarcane Research, Lucknow,

Uttar Pradesh, India

2 Birbal Sahni Institute of Palaeosciences, Lucknow,

Uttar Pradesh, India

3 Amity University, Lucknow, Uttar Pradesh, India 